\title{
An Improved, Practical, and Scalable Five-Step Synthesis of Psilocybin
}

\author{
Alexander M. Sherwood \\ Poncho Meisenheimer \\ Gary Tarpley \\ Robert B. Kargbo*(1) \\ Usona Institute, 2780 Woods Hollow Road, Madison, \\ WI 53711, USA \\ robert.kargbo@usonainstitute.org
}
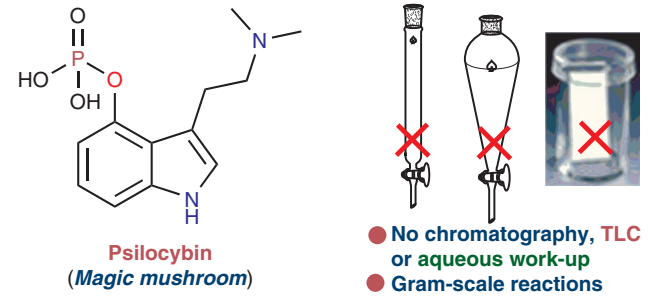

Received: 02.11.2019

Accepted after revision: 12.12 .2019

Published online: 08.01.2020

DOI: 10.1055/s-0039-1691565; Art ID: ss-2019-n0488-psp

License terms: (C) $९ \$$

(c) 2020. The Author(s). This is an open access article published by Thieme under the terms of the Creative Commons Attribution-NonDerivative-NonCommercial-License, permitting copying and reproduction so long as the original work is given appropriate credit. Contents may not be used for commercial purposes or adapted, remixed, transformed or built upon. (https://creativecommons.org/licenses/by-nc-nd/4.0/)

Abstract Described herein is an improved synthesis of 3-[2-(dimethylamino)ethyl]-1H-indol-4-yl dihydrogen phosphate (psilocybin). The protocol outlines: synthesis of multigram quantities of psilocybin, identification of critical in-process parameters, and isolation of psilocybin without the use of chromatography, TLC, or aqueous workup. The synthesis furnishes psilocybin in five steps in $23 \%$ overall yield from an inexpensive acetoxyindole starting material. With specific focus on process control and impurity fate and removal, the improved procedure is amenable to providing high-quality psilocybin.

Key words psilocybin, psilocin, phosphorylation, hydrogenolysis, reduction, quenching method, major depressive disorder

Psilocybin (1) is a psychoactive natural product found in polyphyletic group of fungi that has been used as an entheogen and hallucinogenic drug. ${ }^{1}$ When ingested, psilocybin (1) functions as a prodrug that is rapidly dephosphorylated to psilocin (7). ${ }^{2}$ Psilocin, which is the pharmacologically active ingredient is structurally related to a number of similar compounds depicted in Figure 1 such as lysergic acid diethylamide [LSD (2)], N,N-dimethyltryptamine [DMT (3)], and 5-methoxy- $\mathrm{N}, \mathrm{N}$-dimethyltryptamine [5- $\mathrm{CH}_{3} \mathrm{O}-$ DMT (4)], which are all known to induce similar psychoactive effects in humans. A common feature to all of these compounds is their capacity to occasion mystical experiences, which has been correlated with positive therapeutic outcomes. ${ }^{3}$ Since the 1960s when Sandoz laboratories supplied psilocybin, the psychiatric community has reported numerous studies into the therapeutic use of psilocybin. ${ }^{4}$ In particular, studies linking psilocybin and activity in serotonergic neurons ${ }^{5}$ and the sensory cortex in general suggested potential implications for treating depression. ${ }^{6}$ In con- trast to standard antidepressants, which are often taken daily, a single dose of psilocybin has been reported to produce a large antidepressant effect that may last up to six months. ${ }^{7}$ Rates of adherence to psilocybin-assisted therapy when administered in supervised and monitored in clinical settings are relatively high compared to standard therapy. ${ }^{8}$

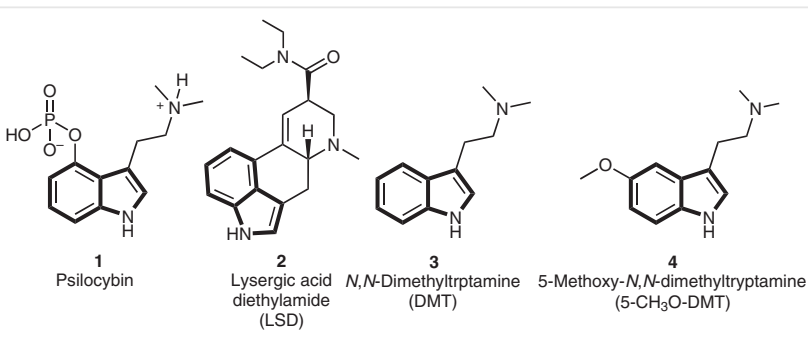

Figure 1 Representative structures of indole-based psychedelics

The prevalence of depression has risen in every country $^{9}$ and major depressive disorders (MDD) is currently the leading cause of disability worldwide. ${ }^{10}$ An estimated 60 $70 \%$ of suicides in the United States are from people considered clinically depressed. ${ }^{11}$ Suicide is one of the top ten causes of death in the United States. ${ }^{12}$ This troubling statistic is exacerbated, in part, by opioid addiction, drug overdoses, and MDD. The current treatment for addiction, depression, and anxiety often fail to affect a meaningful quality of life. Consequently, the increase in anecdotal and scientific reports suggesting that psychedelics have therapeutic potential in treatment of these indications have garnered interest in pursuing regulatory changes to enable further research of their clinical use. ${ }^{13}$

To further scientific and clinical research on psychedelics, we embarked on clinical development of psilocybin for the treatment of MDD in participants considered medically healthy and in patients with potentially life-threatening cancer diagnosis. As a result, a practical large-scale synthesis of 1 was needed. Though there were literature precedents that described the synthesis of $\mathbf{1}$, it became 
critical to modify the procedures in order to provide sufficient quantities of compound with characterization data and quality to meet strict regulatory requirements and support clinical operations.

To date, several syntheses of $\mathbf{1}$ have been reported. ${ }^{14}$ Most commonly, the classical Speeter-Antony tryptamine synthesis (STS) has been used to produce psilocin (7) reliably. ${ }^{15}$ The subsequent phosphorylation of psilocin (7) has been historically problematic, owing in part to its labile nature. The use of a benzyl-protected phosphorylating reagent and deprotection has been demonstrated in all previous literature reports. Hofmann first reported the use of O,O-dibenzylphosphoryl chloride in the penultimate phosphorylation step. More recently, Nichols alternatively used tetrabenzyl pyrophosphate (TBPP), citing various undesirable properties of 0,0 -dibenzylphosphoryl chloride. ${ }^{16}$ Furthermore, refinement of the Nichols' procedure by Shirota was published several years later. ${ }^{17}$ In this report, Shirota identified and characterized an unexpected rearrangement product formed by the migration of the $O$-benzyl group to the dimethylamine functionality (Scheme 1 ) resulting in a zwitterionic isomer. The limited solubility of zwitterionic intermediate 9 allowed isolation by trituration and simple filtration, which circumvented a difficult chromatographic purification at this step.
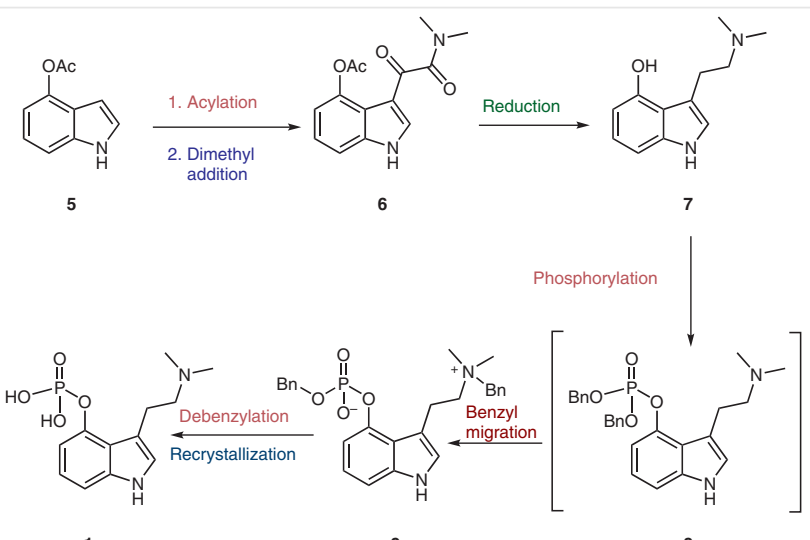
1

9

Scheme 1 General synthetic approaches to psilocybin (1)

In our hands, exact reproduction of the procedure by Shirota fell short of the expected yield and purity. Consequently, we have developed a suitable procedure, which synthesized sufficient quantities of $\mathbf{1}$ in high purity (99.9\%) to support our clinical operations. This report describes potential problems in each step and defines critical process parameters that inform large-scale synthesis of the final active pharmaceutical ingredient (API, 1) in high purity without chromatographic purification.

The general synthetic approach to 1 remained consistent with the previously reported route (Scheme 1), utilizing the classical STS approach from 4-acetoxyindole (5) to obtain 7 with subsequent phosphorylation by TBPP. When benzylated compound $\mathbf{9}$ was subjected to hydrogenolysis, compound 1 was obtained cleanly.

Starting from acetoxyindole (5), we found that controlling residual oxalyl chloride in the initial acylation reaction was crucial for the stability of intermediate $\mathbf{1 0}$ (Scheme 2 ). In the presence of traces of oxalyl chloride, intermediate $\mathbf{1 0}$ decomposes rapidly, which was undesirable for a largescale campaign where storage of intermediates may last from few hours to days. Additionally, removal of excess oxalyl chloride mitigates a side reaction during the dimethylamine addition, which gave a tetramethyloxamide sideproduct along with compound $\mathbf{6}$, which was difficult to remove during purification. Furthermore, the presence of tetramethyloxamide during the lithium aluminum hydride $\left(\mathrm{LiAlH}_{4}\right)$ reduction of compound $\mathbf{6}$ to compound 7, caused excess consumption of $\mathrm{LiAlH}_{4}$, which led to incomplete reaction and by-products. Using optimized conditions, we found thorough washing of the glyoxal chloride with heptane/MTBE gave clean yellow solid $\mathbf{1 0}$ that was stable and stored for several days without decomposition.

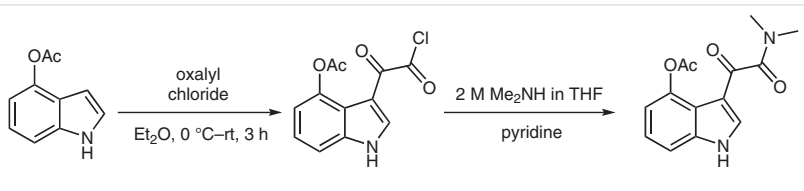

$$
5
$$

10

Scheme 2 Synthesis of 3-[2-(dimethylamino)-2-oxoacetyl]-1H-indol4-yl acetate (6)

In the reaction of dimethylamine with glyoxal chloride 10 , ketoamide 6 was conveniently isolated directly from the reaction mixture as a crude solid, which was reslurried with water to remove pyridine salts, followed by heptane and ethyl acetate to remove any additional organic impurities. This process ultimately provided $\mathbf{6}$ in over $80 \%$ yield and $96 \%$ purity from 4 -acetoxy indole (5). In this form, 6 has been stored for up to several months under ambient conditions with no apparent degradation. Though this material was of sufficient purity to be used in subsequent steps, $\mathbf{6}$ could be further purified by recrystallization from isopropyl alcohol to afford $70 \%$ of a crystalline solid in $>99 \%$ purity. Compound $\mathbf{6}$ displays the characteristics of possibly appropriate starting material in current Good Manufacturing Practices (cGMP) because it is readily purifiable, highly stable, and easily characterizable.

Initial attempts at reduction of compound $\mathbf{6}$ using $\mathrm{LiAlH}_{4}$ in refluxing THF for 2 hours showed a single chromatographic peak by LCMS with the expected protonated product mass (205), but also an intense signal with 203 (Scheme 3). Attempted isolation of product from this reaction gave an impure material with only low levels of expected signals for compound $\mathbf{7}$ detectable by NMR. Upon further investigation using analytical HPLC with an optimized 
gradient, an intermediate with similar retention was detected alongside 7 . Under prolonged refluxing in THF $(>24$ $\mathrm{h}$ ), this intermediate eventually disappeared and a significant amount of product $\mathbf{7}$ was seen. Due to stability concerns, prolonged refluxing in THF was ultimately undesirable. Attempts to add excess $\mathrm{LiAlH}_{4}$ during the reaction to affect completion was unfruitful. Fortunately, 2-methyltetrahydrofuran (2- $\left.\mathrm{CH}_{3}-\mathrm{THF}\right)$, with a higher boiling point compared to THF, was found to be an acceptable substitute solvent. With good in process control (IPC) by HPLC for reaction monitoring in place, it was determined that after $\mathrm{LiAlH}_{4}$ addition at $0{ }^{\circ} \mathrm{C}$ and subsequent warming to ambient temperature, only the major intermediate and approximately $5 \%$ of $\mathbf{7}$ was present in the reaction mixture. The reaction was intentionally stalled at this stage to isolate the intermediate. We found the intermediate impurity to preferentially retain on silica gel and aluminum cake compared to 7 . We isolated and analyzed the intermediate by ${ }^{1} \mathrm{H}$ and ${ }^{13} \mathrm{C}$ NMR and found it to be the $\beta$-hydroxy compound $\mathbf{1 1}$ (Scheme 3).
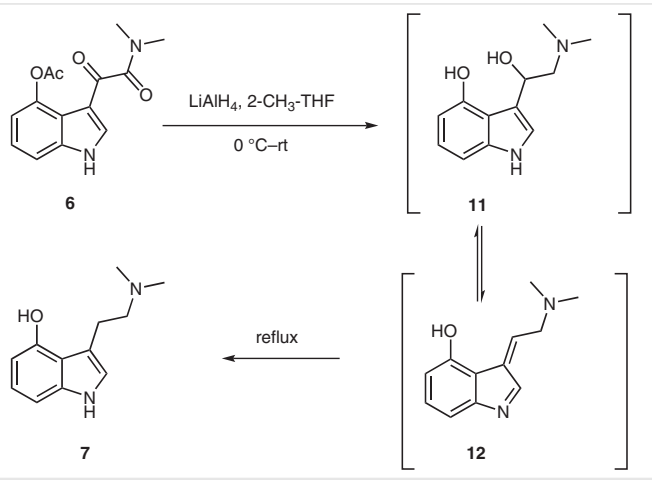

Scheme 3 Synthesis of key psilocin intermediate 7

The detected mass signal of 203 (12) from the LCMS analysis of $\mathbf{7}$ in the crude reaction mixture could be explained by possibly the in-source elimination of the relatively labile hydroxyl group (Scheme 3) during the LCMS run. Furthermore, this elimination process may represent the most likely rate limiting step in the conversion of $\mathbf{1 1}$ into 7, given the difficulty of $\mathrm{LiAlH}_{4}$ directly reducing a hydroxyl group. Refluxing for 3 hours in the higher-boiling 2$\mathrm{CH}_{3}$-THF solvent was sufficient to give a conversion of $>95 \%$ by HPLC. This was a significant breakthrough that led to compound $\mathbf{7}$ in purity of $>99 \%$ after the requisite workup procedure. In our hands, compound $\mathbf{7}$ was found to be unstable if not isolated cleanly in a timely manner as the residual byproduct from the $\mathrm{LiAlH}_{4}$ reduction may contribute to its decomposition.

Several standard quenching protocols for the $\mathrm{LiAlH}_{4}$ reductions were attempted. The Fieser workup ${ }^{18}$ gave higher purity, however, recovery of the product was very low and much of the material became trapped in the filter cake. Furthermore, holding the product on the filter cake for more than a few hours led to decomposition of the product. It was found that a careful wash with $7 \mathrm{~N} \mathrm{NH}_{3}$ in methanol and DCM was sufficient to free the product from the aluminum salts in the filter cake. With this protocol (Procedure A), compound $\mathbf{7}$ was obtained in high yield and purity, but was found to darken quickly despite retaining purity by HPLC.

An alternative quench protocol employing wet THF and silica gel (Procedure B) was later identified to be superior to the Fieser process. Using this protocol, 7 was obtained by simple filtration as a white solid of higher purity compared to material isolated by the Fieser workup, which typically required reslurry to obtain higher yield.

The next step of the phosphorylation-rearrangement protocol in the conversion of $\mathbf{7}$ into $\mathbf{9}$ via intermediate $\mathbf{8}$, originally described by Shirota was not consistently reproducible on scale. Careful monitoring of the reaction progress by LCMS rather than TLC ${ }^{16}$ was advantageous in establishing conditions for this reaction that were reproducible and scalable. With the proper IPC in place, it became possible to accurately monitor reaction progress and side reactions. Careful control of the temperature profile of the reaction was found to be most critical in the smooth conversion of $\mathbf{7}$ into $\mathbf{9}$ while minimizing unwanted side reactions given the highly reactive nature of both the tetrabenzyl pyrophosphate (TBPP) and the lithium salt of $\mathbf{7}$ (Scheme 4).

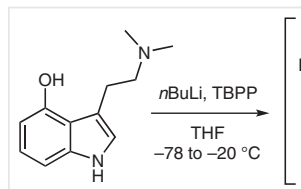

7

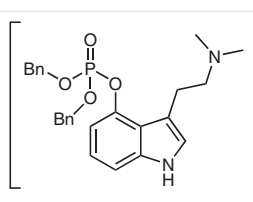

8

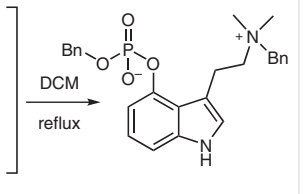

9
Scheme 4 Synthesis of zwitterionic intermediate 9

We found that holding the reaction at $-78{ }^{\circ} \mathrm{C}$ during butyllithium addition followed by TBPP addition and allowing the mixture to stir for 1.5 hours prior to temperature rise to $-20^{\circ} \mathrm{C}$ led to clean conversion. The reaction was quenched with ethyl acetate at $-20^{\circ} \mathrm{C}$ rather than the reported $0{ }^{\circ} \mathrm{C}$, and filtration of the precipitated inorganic solids drowned out compound $\mathbf{8}$ in the filtrate. The intermediate $\mathbf{8}$ was suspended in DCM and heated with heat gun for 5 minutes and then slowly cooled to room temperature prior to being held at $0{ }^{\circ} \mathrm{C}$. This process led to complete conversion of $\mathbf{8}$ into the zwitterionic compound $\mathbf{9}$. On the other hand, in earlier trial reactions where impure intermediate $\mathbf{8}$ was utilized, the rearrangement reaction gave incomplete conversions into $\mathbf{9}$ and took several days to accomplish. Furthermore, if the hot solution was quickly cooled to room temperature, a suspension with very small particle size was obtained, which prolonged filtration time. We obtained complete conversion to crude solid 9, and further trituration with DCM afforded pure compound $\mathbf{9}$. The color of compound $\mathbf{9}$ was affected by traces of compound $\mathbf{7}$, which is prone to oxidation and can 
give variable color. In addition, excess TBPP was detrimental to the reaction as it produced phosphate by-products, including dibenzyl phosphate (DBP) that not only impeded conversion into 9 but also affected other downstream processes.

Furthermore, we examined the timing of the reaction, which required several hours from $-78{ }^{\circ} \mathrm{C}$ to $-20{ }^{\circ} \mathrm{C}$, based on our initial findings. We questioned why the very reactive reactants would require such a lengthy timing for completion. To investigate that question, we removed the dry-ice bath after the addition of the TBPP and then rinsed out the dry-ice coating around the round-bottomed flask. We observed suspension of the TBPP at $-78{ }^{\circ} \mathrm{C}$, which was indicative of partial solubility of the TBPP at that temperature. We monitored the reaction as it warms up relatively quickly and also removed any ice buildup around the round-bottomed flask. The disappearance of the suspended TBPP correlated to the conversion into 8 . At $-50{ }^{\circ} \mathrm{C}$, when we observed no traces of suspended TBPP, the reaction was complete in less than 30 minutes. This implies that a solution of TBPP can be added at $-50{ }^{\circ} \mathrm{C}$ rather than addition of solid TBPP according literature precedents. Controlled addition of substrate is always a preferred protocol on scale, if possible, since it can minimize isothermic reactions. More so, addition of a solution of TBPP makes the protocol amenable to flow chemistry, where both reactants could come in at $50{ }^{\circ} \mathrm{C}$ and then a quench line with EtOAc could safely deliver the desired product.

With pure $\mathbf{9}$ in hand, catalytic hydrogenolysis of $\mathbf{9}$ to $\mathbf{1}$ was relatively straightforward. Catalytic hydrogenolysis of $\mathbf{9}$ was done using $10 \mathrm{wt} \% \mathrm{Pd} / \mathrm{C}$ catalyst under a balloon of hydrogen (1 atm). The reaction was typically complete in 30 minutes (Scheme 5). Compound $\mathbf{1}$ had low solubility in methanol and during the reaction precipitated from the reaction mixture. Prior to filtration of the catalyst, dilution of the reaction mixture with water helped to solubilize the product.

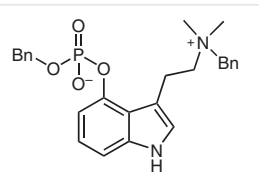

9

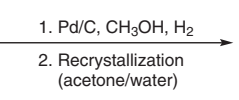

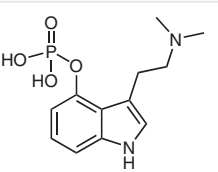

1
Scheme 5 Synthesis of 3-[2-(dimethylamino)ethyl]-1H-indol-4-yl dihydrogen phosphate [psilocybin (1)]

As part of the development of the large-scale manufacture of $\mathbf{1}$, isolation processes that avoid concentration of solutions to dryness was preferable. This is due to ease of transfer and secondly, stability data indicated degradation of psilocybin (1) to psilocin (7) under prolonged thermal condition in solution. A series of water-miscible anti-solvents were screened that could be used to precipitate $\mathbf{1}$ from the aqueous solution. Of the solvents tested, acetone emerged as the most attractive. Zwitterionic $\mathbf{1}$ was virtually insoluble in acetone, which had the additional benefit of also solubilizing minor nonpolar impurities.

Precipitation of $\mathbf{1}$ from the aqueous reaction mixture using acetone typically provided a semi-crystalline solid in about $90 \%$ recovery and $97-98 \%$ purity. Encouraged by the anti-solvent properties of acetone and given the moderate solubility of $\mathbf{1}$ in pure water, we investigated the solvent pair as a recrystallization solvent mixture. It was determined that 80 volumes of a mixture of $30 \%$ water in acetone could completely solubilize 1 at reflux. Upon slowly cooling back $0{ }^{\circ} \mathrm{C}$ over 6 hours, large colorless crystals formed to provide 1 in $70-80 \%$ recovery; HPLC purity analysis of this crystalline solid was typically $>99 \%$. Finally, to provide material suitable for clinical use that is free from any inorganic by-products or trace solvent residues, a final recrystallization using pure water was employed, which typically recovered $50-60 \%$ product. Full certificate of analysis of this material indicated no detectible impurity.

In summary, we have shown the investigative largescale synthesis of psilocybin with the goal of identifying and addressing in-process control and critical process parameters like temperature, appropriate solvent, base and so forth, for each step in the synthesis. Furthermore, identification of critical parameters enabled complete conversions of the reactions with minimal side or by-products, which allowed simple purification of product via trituration, filtration, and recrystallization techniques. Finally, the reliable synthesis of compound 7 provides an attractive combination of synthetic/biocatalysis, in which the direct enzymatic phosphorylation of $\mathbf{7}$ to psilocybin (1) is envisioned. ${ }^{19}$ Such synthetic/biocatalytic investigation is ongoing and the report will be presented in due course.

Reactions were performed using commercially obtained solvents. Unless otherwise stated, all commercially obtained reagents were used as received. ${ }^{1} \mathrm{H}$ and ${ }^{13} \mathrm{C}$ NMR spectra were recorded on a Varian Mercury 400 (at $400 \mathrm{MHz}$ and $100 \mathrm{MHz}$, respectively) and are reported relative to internal $\mathrm{CHCl}_{3}\left({ }^{1} \mathrm{H}, \delta=7.26\right)$, DMSO- $d_{6}\left({ }^{1} \mathrm{H}, \delta=2.50\right)$, $\mathrm{CD}_{2} \mathrm{HOD}\left({ }^{1} \mathrm{H}, \delta=3.31\right)$, and $\mathrm{CDCl}_{3}\left({ }^{13} \mathrm{C}, \delta=77.0\right)$, DMSO- $d_{6}\left({ }^{13} \mathrm{C}, \delta=\right.$ 39.5), $\mathrm{CD}_{3} \mathrm{OD}\left({ }^{13} \mathrm{C}, \delta=49.0\right)$. Data for ${ }^{1} \mathrm{H}$ NMR spectra are reported as follows: chemical shift ( $\delta \mathrm{ppm})$ [multiplicity, coupling constant $(\mathrm{Hz})$, integration]. Standard multiplicity and qualifier abbreviations are used. High-resolution mass spectra were obtained on AB Sciex TripleTOF 5600+. Preparative HPLC was performed with Waters 2535 Quaternary Gradient Module utilizing XBridge PREP C18 Column $5 \mu \mathrm{m}$ (30 mm $\times 250 \mathrm{~mm}$ ). Analytical HPLC was performed with an Agilent 1100 Series HPLC utilizing Phenomenex Synergi ${ }^{\mathrm{TM}} 2.5 \mu \mathrm{m}$ MAX-RP $100 \AA ̊$ columns $(4.6 \mathrm{~mm} \times 50 \mathrm{~mm})$.

\section{3-[2-(Dimethylamino)-2-oxoacetyl]-1H-indol-4-yl Acetate (6)}

A $2000 \mathrm{~mL}$, four-necked, round-bottomed flask was equipped with an overhead stirrer, J-Kem temperature controller, a $250 \mathrm{~mL}$ dropping funnel, and rubber septum through which a positive pressure of dry $\mathrm{N}_{2}$ was inserted. The septum was removed and the flask was charged sequentially with $1 \mathrm{H}$-indol-4-yl acetate $(\mathbf{5} ; 50.1 \mathrm{~g}, 285 \mathrm{mmol}, 1$ equiv) 
and anhyd $\mathrm{Et}_{2} \mathrm{O}(700 \mathrm{~mL})$. The flask was resealed with the septum and is flushed with $\mathrm{N}_{2}$. The suspension was stirred for $10 \mathrm{~min}$ and then cooled to $0{ }^{\circ} \mathrm{C}$ in an ice-water bath for $30 \mathrm{~min}$. The dropping funnel was charged with a solution of oxalyl chloride $(37.1 \mathrm{~mL}, 428 \mathrm{mmol}$, 1.5 equiv) in $\mathrm{Et}_{2} \mathrm{O}(60 \mathrm{~mL})$. The oxalyl chloride solution was added dropwise at a rate sufficient to keep the temperature at or below $5^{\circ} \mathrm{C}$, to minimize formation of dimer and other possible by-product. As the addition progressed, a yellow slurry of $\mathbf{1 0}$ was formed and when the addition was completed, the mixture was stirred for $4 \mathrm{~h}$. The completion of the reaction was assayed by heating an aliquot of the reaction mixture in $\mathrm{MeOH}$ and checking by LCMS the conversion of compound 10 into the corresponding methyl ester [3-(2-methoxy-2-oxoacetyl]$1 \mathrm{H}$-indol-4-yl acetate]. After this time, heptane $(400 \mathrm{~mL})$ was added and the mixture stirred for $30 \mathrm{~min}$ at $0{ }^{\circ} \mathrm{C}$. The yellow solid obtained was quickly filtered and rinsed successively with heptane $(2 \times 300$ $\mathrm{mL}$ ), which was quickly used in the next step. Rinsing the solid with heptane removes excess oxalyl chloride, which prevents the formation of tetramethyloxalylamide in the formation of $\mathbf{6}$. Tetramethyloxalylamide becomes a detrimental impurity, which is difficult to remove in the synthesis of $\mathbf{6}$. Compound $\mathbf{1 0}$ was quickly dissolved in THF $(500 \mathrm{~mL})$ and cooled to $0^{\circ} \mathrm{C}$. A $2.0 \mathrm{M}$ solution of dimethylamine in THF $(175 \mathrm{~mL})$ was added dropwise at a rate sufficient to maintain temperature below $5{ }^{\circ} \mathrm{C}$ in order to minimize side reactions. After the addition was complete, pyridine $(46 \mathrm{~mL})$ in of THF $(100 \mathrm{~mL})$ was added dropwise and the mixture was stirred well for $60 \mathrm{~min}$. Heptane $(600 \mathrm{~mL})$ was added and the flask contents were suction filtered via a Büchner funnel. The filtered residue was transferred into a roundbottomed flask and deionized $\mathrm{H}_{2} \mathrm{O}(1000 \mathrm{~mL})$ was added, stirred for $30 \mathrm{~min}$, and filtered via Büchner funnel. The off-white solid was triturated sequentially for $40 \mathrm{~min}$ in EtOAc $(600 \mathrm{~mL})$ and heptane $(400$ $\mathrm{mL}$ ). The slurry was filtered via Büchner funnel and the solid was dried in an oven at $40{ }^{\circ} \mathrm{C}$ overnight to afford 6 as a light-yellow solid; yield: $66.1 \mathrm{~g}(81 \%) ; \mathrm{mp} 205-207^{\circ} \mathrm{C}$.

IR (KBr): 3236, 1738, 1625, 1428, 1412, 1362, 1217, 854, $772 \mathrm{~cm}^{-1}$.

${ }^{1} \mathrm{H} \mathrm{NMR}\left(400 \mathrm{MHz}, \mathrm{CDCl}_{3}\right): \delta=10.63(\mathrm{~s}, 1 \mathrm{H}), 7.53-7.47(\mathrm{~m}, 1 \mathrm{H}), 7.21-$ $7.11(\mathrm{~m}, 1 \mathrm{H}), 7.07(\mathrm{~d}, J=8.1 \mathrm{~Hz}, 1 \mathrm{H}), 6.93(\mathrm{~d}, J=7.7 \mathrm{~Hz}, 1 \mathrm{H}), 3.02(\mathrm{~d}$, $J=1.4 \mathrm{~Hz}, 3 \mathrm{H}), 2.92(\mathrm{~d}, J=1.4 \mathrm{~Hz}, 3 \mathrm{H}), 2.51(\mathrm{~s}, 3 \mathrm{H})$.

${ }^{13} \mathrm{C}$ NMR $\left(100 \mathrm{MHz}, \mathrm{CDCl}_{3}\right): \delta=185.38,170.91,168.47,144.26$, 139.23, 138.22, 124.72, 118.25, 115.99, 113.44, 110.83, 37.45, 34.20, 21.55.

HRMS (ESI): $m / z$ calcd for $\mathrm{C}_{14} \mathrm{H}_{14} \mathrm{~N}_{2} \mathrm{O}_{4}(\mathrm{M}+\mathrm{H})^{+}$: 275.1026; found: 275.1028 .

\section{3-[2-(Dimethylamino)ethyl]-1H-indol-4-ol (Psilocin, 7)}

Procedure A: A $2000 \mathrm{~mL}$, four-necked, round-bottomed flask was equipped with an overhead stirrer, J-Kem temperature controller, a $250 \mathrm{~mL}$ dropping funnel, and rubber septum through which a positive pressure of dry $\mathrm{N}_{2}$ was inserted. The septum was removed and the flask charged sequentially with 3-[2-(dimethylamino)-2-oxoacetyl]$1 \mathrm{H}$-indol-4-yl acetate $(\mathbf{6} ; 31.5 \mathrm{~g}, 115 \mathrm{mmol})$ and $2-\mathrm{CH}_{3}$-THF $(1000$ $\mathrm{mL})$. The flask was immersed in an ice-bath at $0{ }^{\circ} \mathrm{C}$ and a solution of $2.3 \mathrm{M} \mathrm{LiAlH}_{4}$ in $2-\mathrm{CH}_{3}$-THF $(140 \mathrm{~mL}, 322 \mathrm{mmol})$ was added through the $250 \mathrm{~mL}$ dropping funnel. The dropping funnel was rinsed with additional 2- $\mathrm{CH}_{3}$-THF $(20 \mathrm{~mL})$. The $\mathrm{LiAlH}_{4}$ solution was added dropwise at a rate to maintain a temperature below $20^{\circ} \mathrm{C}$. After the addition, the ice-water bath was removed and the mixture stirred for $30 \mathrm{~min}$. Analytical HPLC indicated a single major peak, which has been found to be the intermediate compound $\mathbf{1 1}$ ( $\beta$-hydroxypsilocin intermediate). The light-yellow solution was heated to reflux $\left(80^{\circ} \mathrm{C}\right)$ with a heating mantle and became ivory-colored after $3 \mathrm{~h}$. Accumulation of yellow solids was observed on the sides of the round-bottomed flask.
The reaction mixture was assayed by analytical HPLC, which showed completion of $>90 \%$ to product peak 7 . The heating mantle was removed, and the flask was allowed to cool to $50{ }^{\circ} \mathrm{C}$. The flask was again chilled to $20^{\circ} \mathrm{C}$. The reaction was quenched by sequential addition of 3 drops of aq $1 \mathrm{M} \mathrm{NaOH}$ and 3 drops of deionized $\mathrm{H}_{2} \mathrm{O}$. The mixture was diluted with THF (500 mL) and stirred for $20 \mathrm{~min}$. The mixture was filtered via Büchner funnel and the filtrate was kept under $\mathrm{N}_{2}$. The filter cake was quickly reslurried with $200 \mathrm{~mL}$ of [10\% solution of (7\% ammonia in $\mathrm{MeOH})$ in $\mathrm{CH}_{2} \mathrm{Cl}_{2}$ ] and THF $(500 \mathrm{~mL})$. The filtrates were then combined and concentrated to give a green solid. The solid was triturated with 1:1 EtOAc/heptane $(50 \mathrm{~mL})$, then filtered via Büchner funnel. The dark green solid was dried in an oven at $40{ }^{\circ} \mathrm{C}$ overnight to provide dry psilocin (7) as a dark green solid; yield: 20.7 $\mathrm{g}(91 \%) ; \mathrm{mp} 167-169^{\circ} \mathrm{C}$.

IR (KBr): 3398, 3264, 2952, 1574, 1467, 1353, 1261, 1041, $736 \mathrm{~cm}^{-1}$.

${ }^{1} \mathrm{H} \mathrm{NMR}\left(400 \mathrm{MHz}, \mathrm{CDCl}_{3}\right): \delta=13.60(\mathrm{~s}, 1 \mathrm{H}), 8.05(\mathrm{~s}, 1 \mathrm{H}), 7.08(\mathrm{t}, J=$ $7.8 \mathrm{~Hz}, 1 \mathrm{H}), 6.91-6.82(\mathrm{~m}, 2 \mathrm{H}), 6.60(\mathrm{~d}, J=7.7 \mathrm{~Hz}, 1 \mathrm{H}), 3.01-2.94(\mathrm{~m}$, $2 \mathrm{H}), 2.76-2.69(\mathrm{~m}, 2 \mathrm{H}), 2.40(\mathrm{~s}, 6 \mathrm{H})$.

${ }^{13} \mathrm{C}$ NMR $\left(100 \mathrm{MHz}, \mathrm{CDCl}_{3}\right): \delta=152.12,139.07,123.54,120.88$, 117.52, 114.56, 106.46, 102.43, 61.69, 45.35, 25.19.

HRMS (ESI): $m / z$ calcd for $\mathrm{C}_{12} \mathrm{H}_{16} \mathrm{~N}_{2} \mathrm{O}(\mathrm{M}+\mathrm{H})^{+}$: 205.1335; found: 205.1338 .

\section{Compound 11 ( $\beta$-Hydroxypsilocin)}

Intermediate $\mathbf{1 1}$ was isolated by performing essentially the same reaction sequence described for compound $\mathbf{7}$ on a smaller scale except it was stirred at rt instead of reflux for $4 \mathrm{~h}$. Following quench, the filtrate was concentrated, and the residue was purified by flash column chromatography $\left(\mathrm{SiO}_{2}, 100: 10: 1 \mathrm{CH}_{2} \mathrm{Cl}_{2} / \mathrm{CH}_{3} \mathrm{OH} / \mathrm{NH}_{4} \mathrm{OH}\right)$ to provide 11 as a gray solid; $\mathrm{mp} 172-174{ }^{\circ} \mathrm{C}$.

IR (KBr): 3374, 3257, 1468, 1359, 1242, 1052, 1001, $739 \mathrm{~cm}^{-1}$.

${ }^{1} \mathrm{H}$ NMR (400 MHz, DMSO- $d_{6}$ ): $\delta=10.79(\mathrm{~s}, 1 \mathrm{H}), 7.10(\mathrm{~d}, J=2.4 \mathrm{~Hz}, 1$ $\mathrm{H}), 6.88(\mathrm{t}, J=7.7 \mathrm{~Hz}, 1 \mathrm{H}), 6.80(\mathrm{dd}, J=8.0,1.1 \mathrm{~Hz}, 1 \mathrm{H}), 6.32(\mathrm{dd}, J=$ 7.5, 1.0 Hz, $1 \mathrm{H}$ ), 5.04 (dd, J = 7.6, $5.0 \mathrm{~Hz}, 1 \mathrm{H}$ ), 3.34 (s, $1 \mathrm{H}$ ), 2.58 (dd, $J=12.5,7.6 \mathrm{~Hz}, 1 \mathrm{H}), 2.45(\mathrm{dd}, J=12.5,5.0 \mathrm{~Hz}, 1 \mathrm{H}), 2.24(\mathrm{~s}, 6 \mathrm{H})$.

${ }^{13} \mathrm{C}$ NMR $\left(100 \mathrm{MHz}\right.$, DMSO- $\left.d_{6}\right): \delta=150.83,139.01,122.74,120.50$, 117.25, 116.10, 103.98, 103.26, 67.93, 65.88, 46.18.

HRMS (ESI): $m / z$ calcd for $\mathrm{C}_{12} \mathrm{H}_{16} \mathrm{~N}_{2} \mathrm{O}_{2}\left(\mathrm{M}+\mathrm{H}-\mathrm{H}_{2} \mathrm{O}\right)^{+}$: 203.1179; found: 203.1186.

Procedure B: The reduction step was carried out using essentially the same protocol described in Procedure A with 6 (40.21 g, $135.2 \mathrm{mmol})$ and $2.3 \mathrm{M} \mathrm{LiAlH}_{4}$ in 2- $\mathrm{CH}_{3}$ - THF (188.1 $\left.\mathrm{mL}, 432.5 \mathrm{mmol}\right)$. The reaction was quenched by dropwise addition of THF $/ \mathrm{H}_{2} \mathrm{O}(27: 100,50 \mathrm{~mL})$ at a rate that kept the temperature below $30{ }^{\circ} \mathrm{C}$. Anhyd $\mathrm{Na}_{2} \mathrm{SO}_{4}(100 \mathrm{~g})$ was added followed by silica gel $(50 \mathrm{~g})$ and DCM $(400 \mathrm{~mL})$. The mixture was stirred for $10 \mathrm{~min}$ and was filtered via Büchner funnel. The filter cake was washed with $\mathrm{DCM} / \mathrm{CH}_{3} \mathrm{OH}$ mixture $(9: 1,1500 \mathrm{~mL})$. The filtrates were then combined and concentrated to give a light green solid. The solid was triturated with 1:1 EtOAc/heptane $(50 \mathrm{~mL})$, then filtered via Büchner funnel. The off-white solid was dried in an oven at $40{ }^{\circ} \mathrm{C}$ overnight to provide dry psilocin (7) as an off-white solid; yield: $21.6 \mathrm{~g}(77 \%)$; 99.2\% HPLC purity.

Characterization consistent with report in Procedure A.

\section{Benzyl \{3-[2-(Benzyldimethylammonio)ethyl]-1H-indol-4-yl\} Phosphate (9)}

A $2000 \mathrm{~mL}$, four-necked, round-bottomed flask was equipped with an overhead stirrer, J-Kem temperature controller, a $100 \mathrm{~mL}$ dropping funnel, and rubber septum through which a positive pressure of dry 
$\mathrm{N}_{2}$ inserted. The septum was removed and the flask was charged sequentially with psilocin $(7 ; 10.3 \mathrm{~g}, 60.2 \mathrm{mmol}$ ) and anhyd THF (500 $\mathrm{mL}$ ). The mixture was stirred for $15 \mathrm{~min}$ and the flask was immersed in a solid $\mathrm{CO}_{2}$ /acetone cooling bath at $-78{ }^{\circ} \mathrm{C}$. When the internal temperature of the reaction reached $-67{ }^{\circ} \mathrm{C}$, a solution of $2.5 \mathrm{M}$ BuLi in hexanes ( $28.9 \mathrm{~mL}, 72.3 \mathrm{mmol}$ ) was added dropwise over a period of a few min and maintained the internal temperature reading below $-60{ }^{\circ} \mathrm{C}$. After stirring the olive-green colored reaction mixture for 10 min, tetrabenzyl pyrophosphate $(35.7 \mathrm{~g}, 66.2 \mathrm{mmol})$ was added in one portion and the mixture was stirred well. After $1.5 \mathrm{~h}$, the solid $\mathrm{CO}_{2}$ /acetone cooing bath was removed and the temperature was allowed to slowly rise to $-25^{\circ} \mathrm{C}$ over $2 \mathrm{~h}$, at which time LCMS showed completion of the reaction to compound $\mathbf{1 5}$ with no trace of compound $\mathbf{1 0}$ in the reaction mixture. Amino bound silica gel (30 g) was added in one portion and the reaction was diluted with EtOAc (600 $\mathrm{mL})$. The dark mixture was filtered through a pad of Celite and washed with EtOAc $(400 \mathrm{~mL})$. The filter cake was reslurried for $10 \mathrm{~min}$ with EtOAc $(400 \mathrm{~mL})$ and again filtered. The combined filtrates were concentrated and transferred into a $500 \mathrm{~mL}$ single-necked roundbottomed flask. The gray oil was redissolved in DCM $(100 \mathrm{~mL})$ and heated with a heat gun to boiling for $5 \mathrm{~min}$. The flask was allowed to reach rt and then held at $4{ }^{\circ} \mathrm{C}$ overnight. The crude grayish-colored zwitterion precipitate 9 was filtered via Büchner funnel, then triturated with DCM $(4 \times 100 \mathrm{~mL})$. The zwitterion precipitate 9 was transferred into a $250 \mathrm{~mL}$ single-necked round-bottomed flask and thoroughly dried in the vacuum oven at $40{ }^{\circ} \mathrm{C}$ overnight to provide a lightpurple solid; yield: $19.2 \mathrm{~g} \mathrm{(63 \% );} \mathrm{mp} 226-228^{\circ} \mathrm{C}$.

IR (KBr): 3031, 2936, 2872, 1233, 1067, 1006, 856, 738, $697 \mathrm{~cm}^{-1}$.

${ }^{1} \mathrm{H}$ NMR $\left(400 \mathrm{MHz}\right.$, DMSO- $\left.d_{6}\right): \delta=11.06(\mathrm{~d}, J=2.5 \mathrm{~Hz}, 1 \mathrm{H}), 7.60-7.54$ (m, $2 \mathrm{H}), 7.53-7.40$ (m, $3 \mathrm{H}), 7.36-7.25(\mathrm{~m}, 4 \mathrm{H}), 7.28-7.19(\mathrm{~m}, 1 \mathrm{H})$, $7.09(\mathrm{t}, J=1.6 \mathrm{~Hz}, 1 \mathrm{H}), 7.01(\mathrm{dd}, J=14.4,7.8 \mathrm{~Hz}, 2 \mathrm{H}), 6.91(\mathrm{t}, J=7.8$ $\mathrm{Hz}, 1 \mathrm{H}), 4.85$ (d, J = 6.4 Hz, $2 \mathrm{H}), 4.68(\mathrm{~s}, 2 \mathrm{H}), 3.72-3.64(\mathrm{~m}, 2 \mathrm{H})$, 3.41-3.26 (m, $3 \mathrm{H}), 3.13$ (s, $6 \mathrm{H})$.

${ }^{13} \mathrm{C}$ NMR $\left(100 \mathrm{MHz}\right.$, DMSO- $\left.d_{6}\right): \delta=148.32,148.25,139.99,139.91$, $139.00,133.47,130.56,129.25,128.88,128.50,127.47,123.60$, 122.15, 119.67, 119.60, 109.09, 109.07, 108.14, 106.29, 67.00, 66.90, $66.85,65.45,49.59,20.74$.

HRMS (ESI): $m / z$ calcd for $\mathrm{C}_{26} \mathrm{H}_{29} \mathrm{~N}_{2} \mathrm{O}_{4} \mathrm{P}(\mathrm{M}+\mathrm{H})^{+}$: 465.1938; found: 465.1935 .

\section{Psilocybin (1)}

Into a $2000 \mathrm{~mL}$ round-bottomed flask was added 9 (16.9 g, 35.6 $\mathrm{mmol}$ ) followed by $\mathrm{CH}_{3} \mathrm{OH}(1200 \mathrm{~mL})$. The mixture was degassed and refilled with $\mathrm{N}_{2} .10 \% \mathrm{Pd} / \mathrm{C}(1.1 \mathrm{~g})$ was added and the mixture was degassed and refilled with a $\mathrm{H}_{2}$ balloon at $1 \mathrm{~atm}$. The reaction mixture was stirred overnight at rt. LCMS showed completion of the reaction with no starting material remaining (Subsequent reactions revealed that the hydrogenolysis was complete after $30 \mathrm{~min}$ ). The flask was degassed, refilled with $\mathrm{N}_{2}$ and the suspension was filtered through a pad of Celite via Büchner funnel. The filter pad was washed with $\mathrm{CH}_{3} \mathrm{OH}$ $(500 \mathrm{~mL})$ and the purple colored filtrate was concentrated and dried overnight under vacuum to give $10.7 \mathrm{~g}$ of crude $\mathbf{1}(106 \%)$. The crude solid was suspended in $i$-PrOH $(200 \mathrm{~mL})$ and boiled for $30 \mathrm{~min}$, then filtered hot $\left(50\right.$ to $\left.60{ }^{\circ} \mathrm{C}\right)$. The collected solid was washed with acetone to give a pale purple colored solid. The purple solid was then suspended in $25 \% \mathrm{CH}_{3} \mathrm{OH} / i$-PrOH and boiled for $30 \mathrm{~min}$ and filtered hot, washing with $25 \% \mathrm{CH}_{3} \mathrm{OH} / i$-PrOH to give a light purple solid. Finally, the solid was recrystallized from $30 \% \mathrm{H}_{2} \mathrm{O}$ in acetone and filtered to give light blue needles. Further recrystallization from $30 \%$ acetone/water gave colorless needles. A final recrystallization from deionized $\mathrm{H}_{2} \mathrm{O}(\sim 50 \mathrm{~mL})$ gave a white solid, which was dried in an oven at $60{ }^{\circ} \mathrm{C}$ for two days to provide 1 as a white solid; yield: $4.9 \mathrm{~g}$ (49\%); 99.9\% HPLC purity; mp $221-223^{\circ} \mathrm{C}$.

IR (KBr): 3365, 3172, 1098, 1040, 919, 856, $811 \mathrm{~cm}^{-1}$.

${ }^{1} \mathrm{H}$ NMR $\left(400 \mathrm{MHz}, \mathrm{D}_{2} \mathrm{O}\right): \delta=7.20(\mathrm{~d}, J=7.9 \mathrm{~Hz}, 1 \mathrm{H}), 7.11(\mathrm{~s}, \mathrm{H}-2,1 \mathrm{H})$, $7.09(\mathrm{t}, J=8.0 \mathrm{~Hz}, 1 \mathrm{H}, \mathrm{H}-6), 6.95(\mathrm{~d}, J=8.0 \mathrm{~Hz}, 1 \mathrm{H}), 3.39(\mathrm{t}, J=8.0, \mathrm{~Hz}$, $\left.2 \mathrm{H}, \mathrm{H}_{2}-2^{\prime}\right), 3.23$ (t, J = 8.0 Hz, $\left.2 \mathrm{H}\right), 2.82(\mathrm{~s}, 6 \mathrm{H})$.

${ }^{13} \mathrm{C}$ NMR (100 MHz, $\mathrm{D}_{2} \mathrm{O}+1$ drop of $\left.\mathrm{CH}_{3} \mathrm{OH}\right): \delta=146.4(\mathrm{~d}, J=6 \mathrm{~Hz}, \mathrm{C}$, split, C-4), 139.4 (C, C-7a), 124.8 (CH, C-6), 123.3 (CH, C-2), 119.1 (d, $J=6 \mathrm{~Hz}, \mathrm{C}$, split, C-3 $), 109.1$ (d, J = 3 Hz, CH, split, C-5 $), 108.6$ (C, C-3), $108.4(\mathrm{CH}, \mathrm{C}-7), 59.7\left(\mathrm{CH}_{2}, \mathrm{C}-2^{\prime}\right), 43.4\left[2 \times \mathrm{CH}_{3}, \mathrm{~N}\left(\mathrm{CH}_{3}\right)_{2}\right], 22.4\left(\mathrm{CH}_{2}, \mathrm{C}-\right.$ $\left.1^{\prime}\right)$.

For a comparison of ${ }^{1} \mathrm{H}$ and ${ }^{13} \mathrm{C}$ NMR spectra data of $\mathbf{1}$ with the literature values, see the Supporting Information.

HRMS (ESI): $m / z$ calcd for $\mathrm{C}_{12} \mathrm{H}_{17} \mathrm{~N}_{2} \mathrm{O}_{4} \mathrm{P}(\mathrm{M}+\mathrm{H})^{+}$: 285.0999; found: 285.0999 .

\section{Acknowledgment}

The authors wish to thank Dr. Nicholas V. Cozzi, Dr. David E. Nichols, and Dr. Paul Daley for their invaluable insights towards the development of this work.

\section{Supporting Information}

Supporting information for this article is available online at https://doi.org/10.1055/s-0039-1691565.

\section{References}

(1) (a) Rucker, J. J. H.; Iliff, J.; Nutt, D. J. Neuropharmacology 2018, 142, 200. (b) Kyzar, E. J.; Nichols, C. D.; Gainetdinov, R. R.; Nichols, D. E.; Kalueff, A. V. Trends Pharmacol. Sci. 2017, 38, 992. (c) Matsushima, Y.; Eguchi, F.; Kikukawa, T.; Matsuda, T. Inflamm. and Regen. 2009, 29, 47.

(2) (a) Dinis-Oliveira, R. J. Drug Metab. Rev. 2017, 49, 84. (b) The LD50/ED50 ratio for aspirin is 199 and 641 for psilocin, which compares favorably to presently approved drugs, see: Palenicek, T.; Horacek, J. Eur. Neuropsychopharm. 2014, 24, 342.

(3) Halberstadt, A. L.; Vollenweider, F. X.; Nichols, D. E. Behavioral Neurobiology of Psychedelic Drugs, 1st ed; Springer: Berlin, 2018.

(4) (a) Thomas, K.; Malcolm, B.; Lastra, D. J. Psychoactive Drugs 2017, 49, 446. (b) Hasler, F.; Bourquin, D.; Brenneisen, R.; Bär, T.; Vollenweider, F. X. Pharmaceut. Acta Helv. 1997, 72, 175.

(5) Trulson, M. E.; Heym, J.; Jacobs, B. L. Brain Res. 1981, 215, 275.

(6) Roiser, J. P.; Rees, G. Curr. Biol. 2012, 22, 231.

(7) Brown, R. T.; Nicholas, C. R.; Cozzi, N. V.; Gassman, M. C.; Cooper, K. M.; Muller, D.; Thomas, C. D.; Hetzel, S. J.; Henriquez, K. M.; Ribaudo, A. S. Clin. Pharmacokinet. 2017, 56, 1543.

(8) (a) Grob, C. S.; Danforth, A. L.; Chopra, G. S.; Hagerty, M.; McKay, C. R.; Halberstadt, A. L.; Greer, G. R. Arch. Gen. Psychiatry 2011, 68, 71. (b) Griffiths, R. R.; Johnson, M. W.; Carducci, M. A.; Umbricht, A.; Richards, W. A.; Richards, B. D.; Cosimano, M. P.; Klinedinst, M. A. J. Psychopharmacol. 2016, 30, 1181. (c) Ross, S.; Bossis, A.; Guss, J.; Agin-Liebes, G.; Malone, T.; Cohen, B.; Mennenga, S. E.; Belser, A.; Kalliontzi, K.; Babb, J.; Su, Z.; Corby, P.; Schmidt, B. L. J. Psychopharmacol. 2016, 30, 1165. (d) Carhart-Harris, R. L.; Bolstridge, M.; Rucker, J.; Day, C. M. J.; Erritzoe, D.; Kaelen, M.; Bloomfield, M.; Rickard, J. A.; Forbes, B.; 
Feilding, A.; Taylor, D.; Pilling, S.; Curran, V. H.; Nutt, D. J. Lancet Psychiatry 2016, 3, 619. (e) Carhart-Harris, R. L.; Goodwin, G. M. Neuropsychopharmacology 2017, 42, 2105. (f) Idell, R. D.; Florova, G.; Komissarov, A. A.; Shetty, S.; Girard, R. B. S.; Idell, S. Med. Hypotheses 2017, 100, 46.

(9) Weissman, M. M.; Wickramaratne, P.; Greenwald, S.; Hsu, H.; Ouellette, R.; Robins, L. N.; Hallmayer, J. JAMA 1992, 268, 3098.

(10) (a) World Health Organization; Depression and Other Common Mental Disorders (2017, February); WHO: Genf, 2017; http://www.who.int/mediacentre/factsheets/fs369/en/.

(b) Kessler, R. C.; Berglund, P.; Demler, O.; Jin, R.; Koretz, D.; Merikangas, K. R.; Water, E. E.; Wang, P. S. JAMA 2003, 289, 3095.

(11) Sudak, H. S. Suicide, In Kaplan \& Sadock's Comprehensive Textbook of Psychiatry, 8th ed., Vol II; Sadock, B. J.; Sadock, V. A., Ed.; Lippincott, Williams \& Wilkins: New York, 2005, 2442-2453.

(12) Akiskal, H. S. Mood Disorders: Historical Introduction and Conceptual Overview, In Kaplan E Sadock's Comprehensive Textbook of Psychiatry, 8th ed., Vol. I; Sadock, B. J.; Sadock, V. A., Ed.; Lippincott, Williams \& Wilkins: New York, 2005, 1559-1575.

(13) Nichols, D. E.; Johnson, M. W.; Nichols, C. D. Clin. Pharmacol. Ther. 2017, 101, 209.

(14) (a) Hofmann, A.; Heim, R.; Brack, A.; Kobel, H.; Frey, A.; Ott, H.; Petrzilka, T.; Troxler, F. Helv. Chim. Acta 1959, 42, 1557. (b) Speeter, M. E.; Anthony, W. C. J. Am. Chem. Soc. 1954, 76,
6208. (c) Hofmann, A.; Frey, A.; Ott, H.; Petrzilka, T.; Troxler, F. Experientia 1958, 15, 397. (d) Ono, M.; Shimamine, M.; Takahashi, K. Bull. Nat. Inst. Hygienic Sci. 1973, 91, 39.

(15) (a) Bartolucci, S.; Mari, M.; Di Gregorio, G.; Piersanti, G. Tetrahedron 2016, 72, 2233. (b) Gathergood, N.; Scammells, P. J. Org. Lett. 2003, 5, 921. (c) Sakagami, H.; Ogasawara, K. Heterocycles 1999, 51, 1131. (d) Furman, S.; Nissim-Bardugo, E.; Zeeli, S.; Weitman, M.; Nudelman, A.; Finkin-Groner, E.; Moradov, D.; Shifrin, H.; Schorer-Apelbaum, D.; Weinstock, M. Bioorg. Med. Chem. Lett. 2014, 24, 2283. (e) Hu, C.; Qin, H.; Cui, Y.; Jia, Y. Tetrahedron 2009, 65, 9075. (f) Troxler, F.; Seemann, F.; Hofmann, A. Helv. Chim. Acta 1959, 42, 2073. (g) Hofmann, A.; Frey, A.; Ott, H.; Petrzilka, T.; Troxler, F. Experientia 1958, 14, 397.

(16) Reaction monitoring by TLC for this reaction was ambiguous. Even though it showed apparent completion, as it was difficult to distinguish mixtures of 0,0 -dibenzylpsilocybin and $O$-monobenzylpsilocybin, see: Nichols, D. E.; Frescas, S. Synthesis 1999, 935.

(17) Shirota, O.; Hakamata, W.; Goda, Y. J. Nat. Prod. 2003, 66, 885.

(18) Fieser, L. F.; Fieser, M. Reagents for Organic Synthesis, Vol. 1; Wiley: New York, 1967, 581-595.

(19) (a) Blei, F.; Baldeweg, F.; Fricke, J.; Hoffmeister, D. Chem. Eur. J. 2018, 24, 10028. (b) Fricke, J.; Blei, F.; Hoffmeister, D. Angew. Chem. Intl. Ed. 2017, 56, 12352. (c) Lenz, C.; Wick, J.; Hoffmeister, D. J. Nat. Prod. 2017, 80, 2835. 